\title{
Editorial
}

\section{Advancements in Photovoltaic Cell and System Technologies}

\author{
Daniel T. Cotfas $\mathbb{D}^{1},{ }^{1}$ Dezso Sera, ${ }^{2}$ Eleni Kaplani $\mathbb{D},{ }^{3}$ Petru A. Cotfas $\mathbb{D}^{1}$, \\ and Alireza Rezaniakolaei ${ }^{2}$ \\ ${ }^{1}$ Electronics and Computers Department, Transilvania University of Brasov, Romania \\ ${ }^{2}$ Department of Energy Technology, Aalborg University, Denmark \\ ${ }^{3}$ Engineering, Faculty of Science, University of East Anglia, UK
}

Correspondence should be addressed to Daniel T. Cotfas; dtcotfas@unitbv.ro

Received 28 November 2019; Accepted 29 November 2019; Published 5 December 2019

Copyright @ 2019 Daniel T. Cotfas et al. This is an open access article distributed under the Creative Commons Attribution License, which permits unrestricted use, distribution, and reproduction in any medium, provided the original work is properly cited.

Renewable energy undergoes a continuous development and improvement being driven by the growth in energy demand, the need to reduce pollution, and the increase in investment and policies at national and international levels. The photovoltaic solar energy lately became an important pillar for renewable energy to reach global and European targets in the share of renewable electricity. The first target for the energy generated by photovoltaic systems is $10 \%$ from the total European electricity production until 2020 [1], and until 2050, 60\% from electricity generation has to be from photovoltaic solar energy and wind [2].

The global cumulative installed PV capacity reached over $500 \mathrm{GW}$ in the end of 2018 following an exponential growth $[3,4]$. In 2018, the $100 \mathrm{GW}$ of a new added PV capacity has been reached for the first time; this was also the third consecutive year when PV had by far the largest new capacity addition among all energy technologies. This trend is expected to continue [3-5]. The price of the PV module is continuously decreasing, so at each doubling of the production, the price goes down by $24 \%[5,6]$. All of these are possible due to the common effort of the researchers, $R \& D$ centers, industry communities, and government policies.

There is ongoing interdisciplinary research on the design of advanced photovoltaic technologies and photovoltaic systems contributing to the increase in cell and module efficiency, PV system reliability and durability, maximization of solar energy harvested, and overall system yield. Furthermore, advanced PV-based configurations and hybrid systems, including PV, Solar Thermoelectric Generators
(STEG), PV/T, and concentrated or conventional PV systems, integrated with STEG, STC, and energy storage can lead to an increase in the electrical and thermal energy generated and in system lifetime.

This special issue includes articles within the scope of advancements in photovoltaic cell and system technologies. These range from articles addressing the increase in photovoltaic cell efficiency through advancements in their structure or composition and enhancements in photovoltaic module performance targeting the decrease in photovoltaic cell temperature by passive cooling using recyclable materials or phase change materials. Optimal solutions for a wide range of applications are presented along with concepts for enhancing the efficiency of the photovoltaic systems and the final energy yield, including among others sun-tracking systems, reflective and refractive systems, the most commonly applied cooling methods, and maximum power point tracking techniques.

\section{Conflicts of Interest}

The editors declare that they have no conflicts of interest regarding the publication of this special issue.

Daniel T. Cotfas

Dezso Sera

Eleni Kaplani

Petru A. Cotfas

Alireza Rezaniakolaei 


\section{References}

[1] EERA Joint Programme Photovoltaic Solar Energy, November 2019, https://www.eera-set.eu/.

[2] IRENA, Global energy transformation: a roadmap to 2050 (2019 edition), International Renewable Energy Agency, Abu Dhabi, 2019.

[3] IEA, Snapshot of global PV markets, Report IEA-PVPS, 2019.

[4] SolarPower Europe, Global Market Outlook For Solar Power I 2019 - 2023, 2019.

[5] Renewables 2019 Global Status Report, REN21 Secretariat, Paris, 2019.

[6] Photovoltaics Report, Fraunhofer Institute for Solar Energy Systems, ISE with support of PSE GmbH, 2019, https://www.ise fraunhofer.de. 

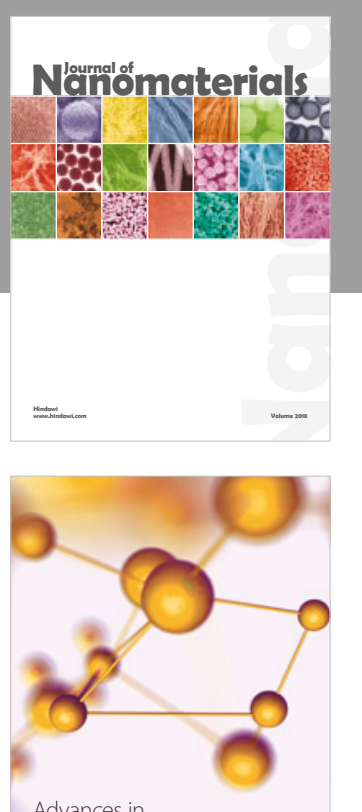

Physical Chemistry
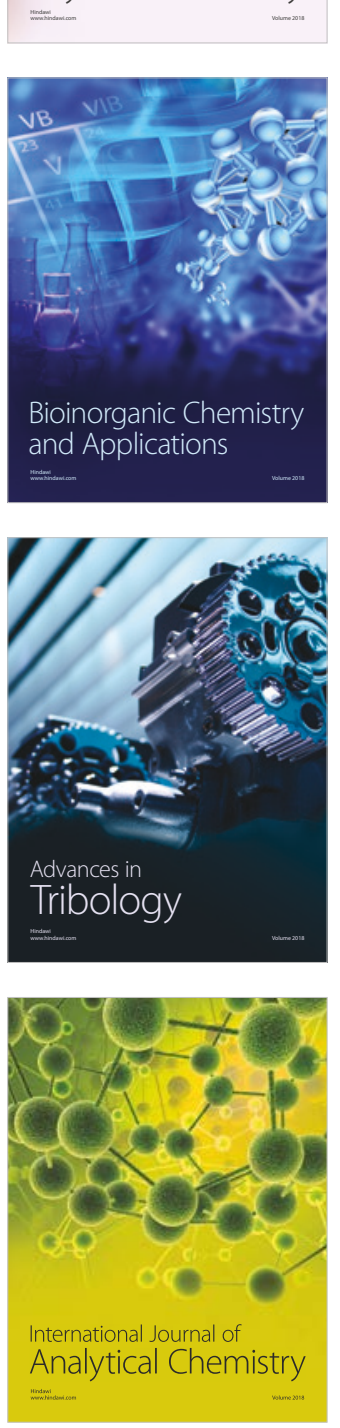

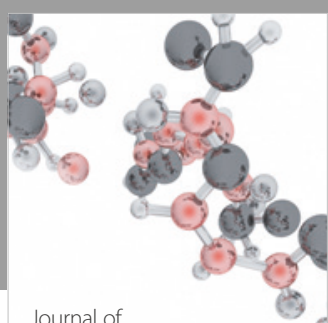

Analytical Methods

in Chemistry

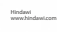

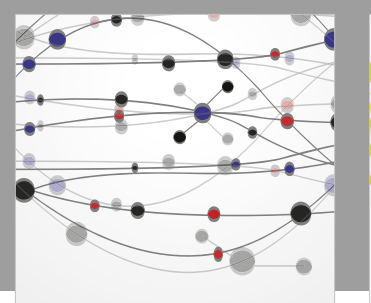

The Scientific World Journal

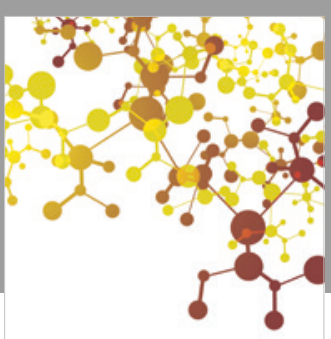

Journal of

Applied Chemistry
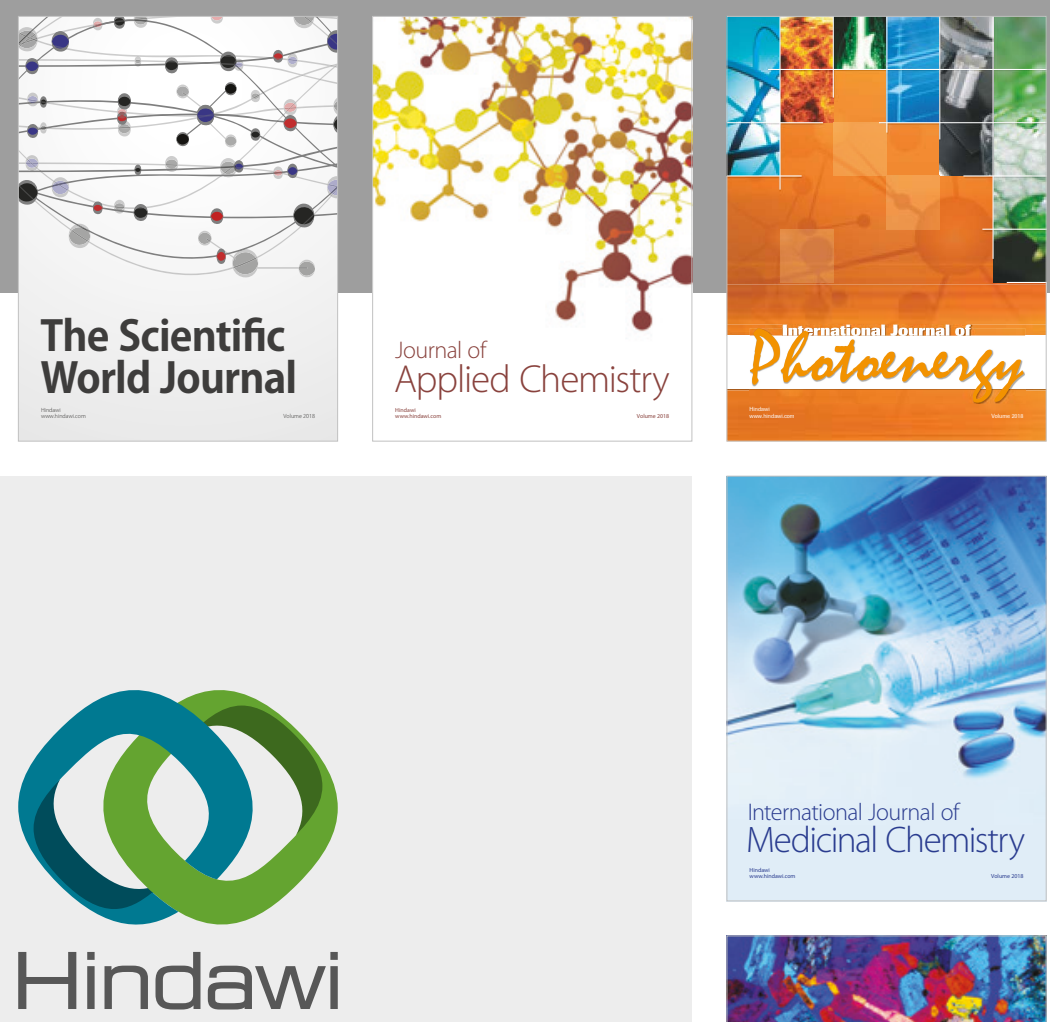

Submit your manuscripts at

www.hindawi.com
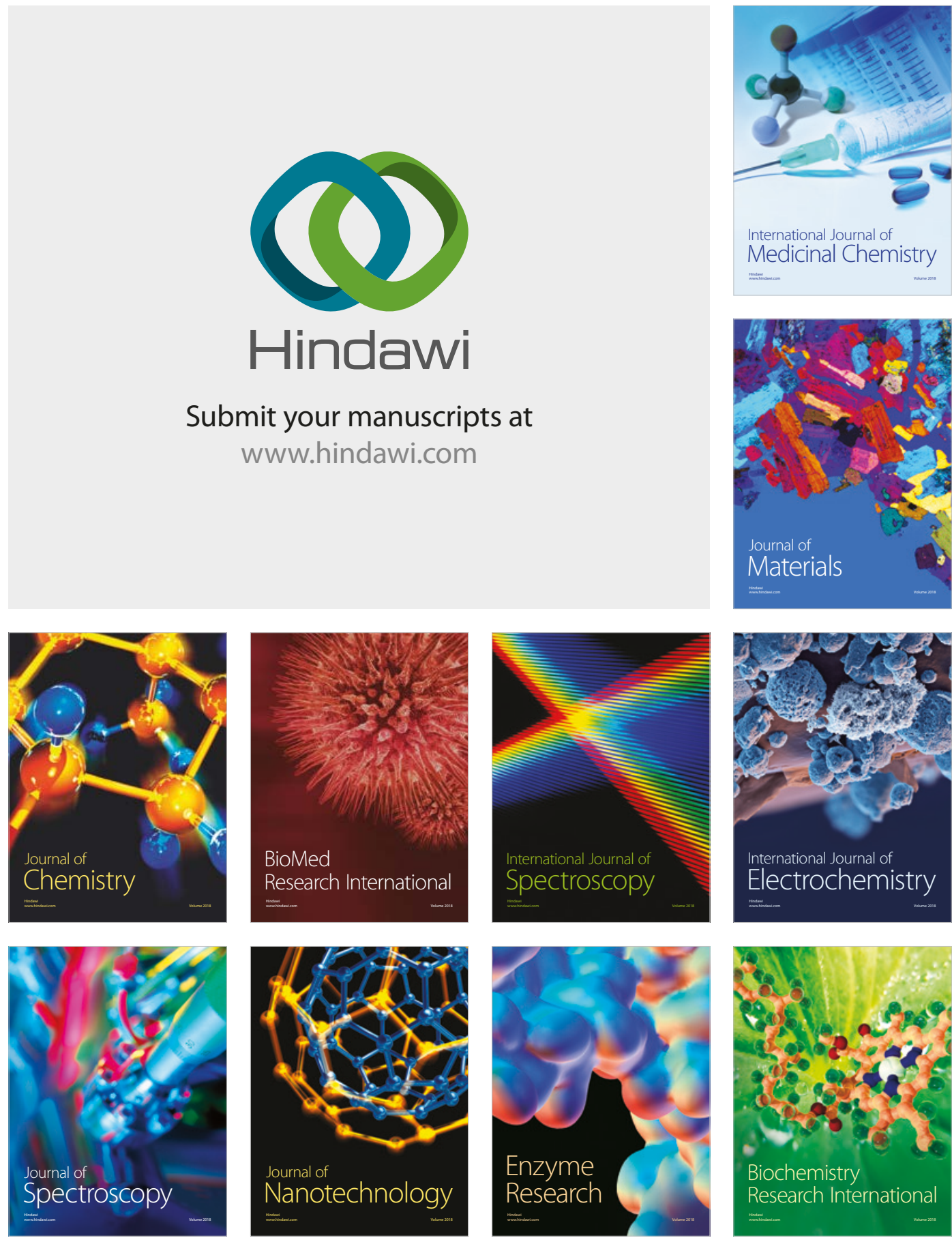
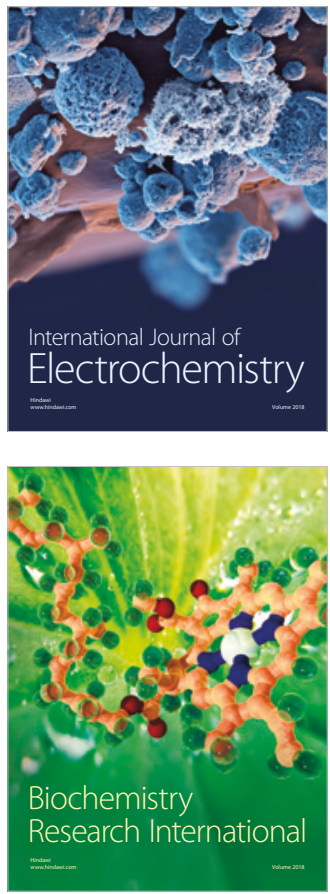